\title{
Cell Cycle Proteins Predict Recurrence in Stage II and III Colon Cancer
}

\author{
Eric J. Th. Belt, MD, PhD ${ }^{1,2}$, Rebecca P. M. Brosens, MD, PhD ${ }^{1}$, Pien M. Delis-van Diemen, MS $^{3}$, Herman Bril, MD, \\ $\mathrm{PhD}^{4}$, Marianne Tijssen, $\mathrm{MS}^{3}$, Dirk F. van Essen, $\mathrm{MS}^{3}$, Martijn W. Heymans, $\mathrm{PhD}^{5}$, Jeroen A. M. Beliën, $\mathbf{P h D}^{3}$, \\ Hein B. A. C. Stockmann, MD, $\mathbf{P h D}^{2}$, Sybren Meijer, $\mathrm{MD}, \mathbf{P h D}^{1}$, and Gerrit A. Meijer, MD, $\mathbf{P h D}^{3}$ \\ ${ }^{1}$ Department of Surgery, VU University Medical Centre, Amsterdam, The Netherlands; ${ }^{2}$ Department of Surgery, \\ Kennemer Gasthuis, Haarlem, The Netherlands; ${ }^{3}$ Department of Pathology, VU University Medical Centre, Amsterdam, \\ The Netherlands; ${ }^{4}$ Department of Pathology, Kennemer Gasthuis, Haarlem, The Netherlands; ${ }^{5}$ Department of \\ Epidemiology and Biostatistics, VU University Medical Centre, Amsterdam, The Netherlands
}

\begin{abstract}
Purpose. To investigate the prognostic value of multiple cell cycle-associated proteins in a large series of stage II and III colon cancers.

Methods. From formalin-fixed, paraffin-embedded tumor samples of 386 patients with stage II and III colon cancer, DNA was isolated and tissue microarrays were constructed. Tissue microarray slides were immunohistochemically stained for $\mathrm{p} 21, \mathrm{p} 27, \mathrm{p} 53$, epidermal growth factor receptor, Her2/Neu, $\beta$-catenin, cyclin D1, Ki-67, thymidylate synthase, and Aurora kinase A (AURKA). Polymerase chain reaction-based microsatellite instability analysis was performed to allow for stratification of protein expression by microsatellite instability status.
\end{abstract}

Results. Overall, low p21, high p53, low cyclin D1, and high AURKA expression were significantly associated with recurrence $(P=0.01, P<0.01, P=0.04$, and $P<0.01$, respectively). In stage II patients who did not receive adjuvant chemotherapy $(n=190)$, significantly more recurrences were observed in case of low-p21 and highp53-expressing tumors $(P<0.01$ and $P=0.03$, respectively). In stage III patients who did not receive chemotherapy, high p53 expression was associated with recurrence $(P=0.02)$, and in patients who received chemotherapy, high AURKA expression was associated with

(C) The Author(s) 2012. This article is published with open access at Springerlink.com

First Received: 8 March 2011;

Published Online: 4 February 2012

G. A. Meijer, MD, PhD

e-mail: ga.meijer@vumc.nl relapse $(P<0.01)$. In patients with microsatellite stable tumors, high levels of p53 and AURKA were associated with recurrence $(P=0.01$ and $P<0.01$, respectively). Multivariate analysis showed p21 (odds ratio 1.6, 95\% confidence interval 0.9-2.8) and AURKA (odds ratio 2.7, 95\% confidence interval $1.3-5.6)$ to be independently associated with disease recurrence.

Conclusions. p21, p53, cyclin D1, and AURKA could possibly be used as prognostic markers to identify colon cancer patients with high risk of disease recurrence.

Currently, the tumor, node, metastasis (TNM) staging system, developed by the American Joint Committee on Cancer (AJCC) and the Union for International Cancer Control (UICC), is the primary method for assessing prognosis for individual patients). ${ }^{1}$ This classification forms the basis for therapeutic decision making in clinical practice. Adjuvant 5-fluorouracil-based chemotherapy has been found to increase 5-year survival in stage III colon cancer patients from $51 \%$ to $64 \%$. $^{2}$ However, no convincing evidence exists for a beneficial effect of chemotherapy in stage II patients; $20-30 \%$ of these patients will develop recurrent disease. ${ }^{3,4}$

Molecular markers reflecting tumor biology may allow for identifying subgroups of patients with high risk of disease recurrence, and may indicate who will or will not benefit from adjuvant therapy.

Proliferation and cell cycle control are central processes in the biology of cancer. ${ }^{5}$ Yet the exact prognostic value of cell cycle-associated markers in colon cancer remains unclear. Numerous studies on these markers have been published, but the majority of these are based on relatively small, heterogeneous series of patients and lack microsatellite 
instability (MSI) analysis and multivariate analysis. The aim of the present study was to investigate the prognostic value of multiple cell cycle-associated proteins in a large series of stage II and III colon cancer patients with determined MSI status.

The panel of markers studied consisted of proteins regulating cell cycle arrest and checkpoint control [p21 (CDKN1A), p27 (CDKN1B), p53 (TP53)], transmembrane and intracellular signaling proteins [epidermal growth factor receptor $(E G F R)$, Her2/Neu (ERBB2), $\beta$-catenin (CTNNB1)], proteins involved in progression of the cell cycle to M-phase [cyclin D1 (CCND1), Ki-67 (MKI67)], and thymidylate synthetase (TS, TYMS) and Aurora kinase A (AURKA).

\section{PATIENTS AND METHODS}

Between 1996 and 2005, a total of 386 patients underwent surgical resection for colon cancer, classified as TNM stage II (T3-4, N0, M0) or III (T1-4, N1-2, M0) according to the TNM staging system by the AJCC and UICC. ${ }^{6}$ Data were collected from clinical and histopathology reports. Patients with positive resection margins and those who were lost to follow-up or who died within 3 months after surgery were excluded. Disease recurrence was defined as either local tumor recurrence or distant metastasis, diagnosed by CT imaging and/or histopathology.

\section{Tissue Microarray}

Tissue microarrays (TMAs) were constructed as described previously. ${ }^{7}$ Briefly, formalin-fixed, paraffinembedded tissue blocks of colon cancer resection specimens were used as donor blocks. Six tissue cylinders with a diameter of $0.6 \mathrm{~mm}$ were punched from morphologically representative tissue areas of each donor block and transferred into the recipient TMA paraffin blocks.

\section{Immunohistochemistry}

Immunohistochemistry was performed on 4- $\mu$ m-thick sections from the TMA blocks. Paraffin was removed from tissue sections with xylene and the sections rehydrated. Endogenous peroxidase activity was quenched with $0.3 \%$ hydrogen peroxide in methanol. For antigen retrieval, the samples were immersed in $10 \mathrm{mM}$ citrate buffer solution and heated in a microwave. Slides were incubated with antibodies specific for p21 (Waf1/Cip1, clone SX118, Dako, Heverlee, Belgium, dilution 1/25), p27 (Kip1, BD USA, 1/2000), p53 (DO-7, Dako, Heverlee, Belgium, 1/500), EGFR (EGFR 113, Novocastra, Newcastle, UK, 1/25), Her2/Neu (SP-3, Neomarkers, Fremont, CA, USA,
1/100), Ki-67 (MIB-1, Dako, Heverlee, Belgium, 1/200), cyclin D1 (Neomarkers, Fremont, CA, USA, 1/50), TS (TS-antibody, kindly provided by Dr. G. W. Aherne, Sutton, UK, 1/100), $\beta$-catenin (17C2, Menarini, Italy, 1/100), AURKA (JLM-28, Novocastra, Newcastle, UK, 1/50).

Negative control slides were incubated with Antibody Diluent only. Next, antibody binding was detected by Powervision Plus system (Immunologic, Duiven, The Netherlands) for p21, cyclin D1, and $\beta$-catenin, EnVision system (Dako, Heverlee, Belgium) for TS and AURKA, and BondMax autostainer (Menarini Diagnostics, Valkenswaard, The Netherlands) for p27, p53, EGFR, Her2/ Neu and Ki-67. Diaminobenzidine was used as a chromagen followed by counterstaining with Mayer hematoxylin.

\section{Evaluation of Protein Expression}

Immunoreactivity was evaluated on each TMA sample. For nuclear staining patterns, extent of staining was scored 0 to 4 according to the percentage of positively stained tumor cells: $0=$ positive staining in $0-1 \% ; 1,1-10 \% ; 2$, 11-25\%; 3, 26-50\%; 4, >50\%. Staining intensity was scored as $0=$ no staining or any intensity in less than $10 \%$ of tumor cells; 1, weak; 2, moderate; 3, strong. For cytoplasmic immunoreactivity, only staining intensity was scored. For protein staining in which both percentage and intensity were assessed, scores were multiplied to produce a weighted score (0-12) for each TMA sample. ${ }^{8}$ Membranous staining was scored 0 to 3 , analogous to the Her2/ Neu scoring system approved by the U.S. Food and Drug Administration. ${ }^{9}$

For p21, p27, p53, and cyclin D1, extent and intensity of nuclear staining were scored. For Ki-67, $\beta$-catenin and AURKA, only extent of positively stained nuclei was assessed, because intensity was similar in all positive nuclei. For Her2/Neu, membranous staining was scored, for EGFR both membranous and cytoplasmic, and for TS only cytoplasmic staining was assessed.

For each patient the highest score of protein expression was used assigned to the 6 tissue sections obtained by the core biopsies taken from each tumor sample. Specimens were examined in a blinded fashion without knowledge of clinical data. To confirm reproducibility, $15 \%$ of all samples were scored a second time by an independent observer.

\section{Assessment of Cutoff Values}

For statistical analysis, scores of protein expression were dichotomized as low or high. Cutoff values for each protein were based on receiver-operating characteristic (ROC) curve analysis and maximum predictive value. ${ }^{10}$ This analysis produced the following cutoff values: p21-high if 
score is $\geq 6, \mathrm{p} 27$-high if score is $\geq 6, \mathrm{p} 53$-high if score is 12 , membranous EGFR-high if score is $\geq 1$, cytoplasmic EGFR-high if score is 3 , Her2/Neu-high if score is $\geq 1$, $\mathrm{Ki}$-67-high if score is 4 , cyclin D1-high if score is $\geq 8$, nuclear $\beta$-catenin-high if score is $\geq 1$, TS-high if score is $\geq 2$, and AURKA-high if score is 4 .

\section{DNA Isolation}

DNA was isolated from formalin-fixed, paraffinembedded colon cancer tissues samples. For each tumor, areas with at least $70 \%$ tumor cells were selected from 4- $\mu \mathrm{m}$ sections. Adjacent serial sections of $10 \mu \mathrm{m}$ were cut, and macro dissected. DNA was isolated as previously described (QIAamp microkit; Qiagen, Hilden, Germany). ${ }^{11}$ DNA concentrations were measured with a Nanodrop-100 spectrophotometer (Isogen, De Meern, The Netherlands).

\section{Microsatellite Instability Analysis}

Tumor samples were analyzed for MSI with the MSI Analysis System, Version 1.2 according to the manufacturer's instructions (Promega, Madison, WI). This PCRbased assay uses five mononucleotide repeat markers to determine MSI status. PCR products were separated by capillary electrophoresis with the ABI 3130 DNA sequencer and output data were analyzed by the accompanying package GeneScan 3100 (Applied Biosystems, Foster City, CA). Tumors were classified as microsatellite instable (MSI) when instability was observed for two or more markers, and microsatellite stable (MSS) when instability was observed for none or only one marker.

\section{Statistical Analysis}

Cohen's kappa coefficient was used to assess agreement on scoring immunohistochemical protein expressions. Differences in proportions between groups were examined by Pearson's chi-square test. Survival rates were displayed and compared by Kaplan-Meier curves and the log rank test. Multivariable analysis was performed by backward stepwise logistic regression. A significance level of 0.05 was used. Statistical analysis was performed with SPSS 17.0 (SPSS, Chicago, IL) and R software (R Foundation for Statistical Computing, Vienna, Austria). The performance of the regression models was evaluated in terms of discrimination by the area under the ROC curve and the explained variation. Bootstrapping techniques were used to correct these measures for optimism to get a more realistic insight in their performance.
TABLE 1 Clinical and pathologic characteristics of 386 stage II and III colon cancer patients

\begin{tabular}{|c|c|c|c|}
\hline Characteristic & $\begin{array}{l}\text { Overall } \\
(n=386)\end{array}$ & $\begin{array}{l}\text { Stage II } \\
(n=226)\end{array}$ & $\begin{array}{l}\text { Stage III } \\
(n=160)\end{array}$ \\
\hline \multicolumn{4}{|l|}{ Sex } \\
\hline Male & $203(52.6)$ & $114(50.4)$ & 89 (55.6) \\
\hline Female & $183(47.4)$ & $112(49.6)$ & $71(44.4)$ \\
\hline \multicolumn{4}{|l|}{ Age (years) } \\
\hline Mean \pm SD & $71.0 \pm 11.9$ & $71.6 \pm 11.8$ & $70.1 \pm 12.0$ \\
\hline Median (range) & $73.0(28.5-94.0)$ & $73.4(28.5-93.3)$ & $72.4(34.5-94.0)$ \\
\hline \multicolumn{4}{|l|}{ Tumor location } \\
\hline Right sided & $173(44.8)$ & $99(43.8)$ & $74(46.2)$ \\
\hline Left sided & $213(55.2)$ & $127(56.2)$ & $86(53.8)$ \\
\hline \multicolumn{4}{|c|}{ Tumor size $(\mathrm{mm})$} \\
\hline Mean \pm SD & $42.2 \pm 19.4$ & $43.5 \pm 20.6$ & $40.4 \pm 17.6$ \\
\hline \multicolumn{4}{|l|}{ Tumor stage } \\
\hline $\mathrm{T} 1$ & $4(1.0)$ & - & $4(2.5)$ \\
\hline $\mathrm{T} 2$ & $19(4.9)$ & - & $19(11.9)$ \\
\hline $\mathrm{T} 3$ & $325(84.2)$ & $201(88.9)$ & $124(77.5)$ \\
\hline $\mathrm{T} 4$ & $38(9.8)$ & $25(11.1)$ & $13(8.1)$ \\
\hline \multicolumn{4}{|l|}{ Nodal stage } \\
\hline No & $226(58.5)$ & $226(100)$ & - \\
\hline N1 & $111(28.8)$ & - & $111(69.4)$ \\
\hline $\mathrm{N} 2$ & $49(12.7)$ & - & 49 (30.6) \\
\hline \multicolumn{4}{|c|}{ No. of nodes examined } \\
\hline Mean \pm SD & $8.9 \pm 5.2$ & $8.4 \pm 5.4$ & $9.7 \pm 4.8$ \\
\hline \multicolumn{4}{|c|}{ Microsatellite stability status ${ }^{\mathrm{a}}$} \\
\hline MSS & $267(80.4)$ & $147(79.5)$ & $120(81.6)$ \\
\hline MSI & $65(19.6)$ & $38(20.5)$ & $27(18.4)$ \\
\hline \multicolumn{4}{|l|}{ Histologic grade } \\
\hline Well & $24(6.2)$ & $18(8.0)$ & $6(3.8)$ \\
\hline Moderate & $302(78.2)$ & $180(79.6)$ & $122(76.3)$ \\
\hline Poor & $60(15.5)$ & $28(12.4)$ & $32(20.0)$ \\
\hline \multicolumn{4}{|c|}{ Mucinous differentiation } \\
\hline Yes & $82(21.2)$ & $48(21.2)$ & $34(21.3)$ \\
\hline No & $304(78.8)$ & $178(78.8)$ & $126(78.8)$ \\
\hline \multicolumn{4}{|l|}{ Ulceration } \\
\hline Present & 297 (76.9) & $170(75.2)$ & $127(79.4)$ \\
\hline Absent & $89(23.1)$ & $56(24.8)$ & $33(20.6)$ \\
\hline \multicolumn{4}{|l|}{ Angioinvasion } \\
\hline Present & $78(20.2)$ & $24(10.6)$ & $54(33.8)$ \\
\hline Absent & $308(79.8)$ & $202(89.4)$ & $106(66.3)$ \\
\hline \multicolumn{4}{|c|}{ Adjuvant chemotherapy } \\
\hline Yes & $122(31.6)$ & $34(15.0)$ & $88(55.0)$ \\
\hline No & $264(68.4)$ & $192(85.0)$ & $72(45.0)$ \\
\hline \multicolumn{4}{|l|}{ Recurrent disease } \\
\hline Yes & $127(32.9)$ & $53(23.5)$ & $74(46.3)$ \\
\hline No & $259(67.1)$ & $173(76.5)$ & $86(53.8)$ \\
\hline \multicolumn{4}{|c|}{ Follow-up (months) } \\
\hline Median (range) & $57.2(3.0-148.6)$ & $63.1(5.3-139.6)$ & $46.9(3.0-148.6)$ \\
\hline
\end{tabular}

Data are presented as $n(\%)$ unless otherwise indicated

${ }^{a}$ Microsatellite instability status was determined in 332 cases 


\section{RESULTS}

\section{Clinicopathologic Features and Disease Recurrence}

Disease recurrence rate in 386 stage II and III colon cancer patients was $32.9 \%$. Stage II patients $(n=226)$ had disease recurrence in $23.5 \%$ of cases, while of stage III patients $(n=160) \quad 46.3 \%$ developed a recurrence $(P<0.01)$ (Table 1).

MSI status could be determined in 332 cases (i.e., $86 \%$ of tumor samples, while attempts to characterize the remaining $14 \%$ failed as a result of insufficient quality of the formalin-fixed, paraffin-embedded-derived DNA material). Of these, 267 were MSS (80.4\%) and 65 MSI (19.6\%). Recurrent disease developed in $36.3 \%$ of patients with MSS tumors, compared to $24.6 \%$ of MSI cases $(P=0.07)$. Considering only stage II patients of whom MSI status was determined $(n=185), 41$ out of 147 patients with MSS tumors showed recurrence, compared to 5 out of 38 patients with MSI tumors (27.9\% and 13.2\%, respectively, $P=0.06$ ). For stage III patients with determined MSI status, no significant difference in recurrence rate was observed between MSI and MSS tumors.

\section{Cell Cycle-associated Proteins and Disease Recurrence}

A high level of agreement on immunohistochemical scores between the two observers was achieved, resulting in a median (all proteins separately scored) Cohen's weighted kappa value: $\mathrm{Kw}=0.67$ (range $0.49-0.84$ ). The number of patients with high and low protein expression levels and disease recurrence rates are listed in Table 2.

Univariate analysis showed low p21, low cyclin D1, high p53, and high AURKA expression to be significantly associated with disease recurrence $(P=0.01, P=0.04$, $P<0.01$, and $P<0.01$, respectively; Fig. 1a-d). p53 expression was inversely associated with p21 $(P=0.02)$ and cyclin D1 expression $(P<0.01)$.

Stage II Patients Considering only stage II patients $(n=226)$, those with p21-low tumors had significantly more recurrences compared to $\mathrm{p} 21$-high tumors $(30.1 \%$ vs. $15.6 \%$, respectively; $P=0.01$; Fig. 1e) and a tendency toward higher recurrence rate was observed for cyclin D1low compared to cyclin D1-high tumors (27.9\% vs. $17.8 \%$, respectively; $P=0.08$ ).

When excluding patients who received adjuvant chemotherapy $(n=34)$ from all stage II patients, p53-high tumors were associated with more recurrences than $\mathrm{p} 53$-low tumors (32.1\% vs. $18.3 \%$, respectively; $P=0.03$; Fig. 1f).

Stage III Patients Focussing on stage III patients, high p53 and high AURKA expression were significantly associated with disease recurrence $(P=0.02$ and $P<0.01$, respectively; Fig. $2 \mathrm{a}$ and $\mathrm{b}$, respectively). For $\mathrm{p} 53$, difference in recurrence rate was mainly attributable to stage III patients who did not receive adjuvant chemotherapy $(n=72)$ as recurrence rate for patients with p53-high tumors was $59.4 \%$ compared to $30.8 \%$ for patients with p53-low tumors $(P=0.02)$. Disease-free survival (DFS) of stage III patients with high p53 expressing tumors who received chemotherapy was not different from those without chemotherapy $(P=0.5)$. DFS was also similar between patients with low p53 tumors receiving chemotherapy and those without chemotherapy $(P=0.6)$ (Fig. 2c).

For AURKA, difference in recurrence rate was mainly attributable to stage III patients who did receive chemotherapy as recurrence was observed in AURKA-high tumors in $54.7 \%$, compared to $17.6 \%$ in AURKA-low tumors $(P<0.01)$. DFS of stage III patients with high AURKA expressing tumors who received chemotherapy was not different from those without chemotherapy $(P=0.5)$. DFS was also similar between patients with low AURKA tumors receiving chemotherapy and those without chemotherapy $(P=0.5)$ (Fig. 2d).

Multivariable analysis included all protein expression levels, disease stage, tumor location, lymph node yield [high $(\geq 12)$ vs. low $(<12)$ ], MSI status, angioinvasive growth and chemotherapy treatment. The following factors are independently associated with disease recurrence: disease stage [odds ratio (OR) 1.8, 95\% confidence interval (CI) 1.0-3.0], low lymph node yield (OR 1.8, 95\% CI 1.0-3.4), angioinvasive growth (OR 3.5, 95\% CI 1.8-6.5), AURKA (OR 2.7, 95\% CI 1.3-5.6) and p21 (OR 1.6, 95\% CI 0.9-2.8). The area under the ROC curve of this model is 0.72 ( 0.71 after correction for optimism) and the explained variation is $20 \%$ (17\% after correction for optimism).

\section{Protein Expression and Disease Recurrence Stratified by MSI Status}

Low p21, high p27, high p53, and low cyclin D1 expression were observed in $63.7 \%, 77.4 \%, 52.1 \%$, and $91.6 \%$ of all (stage II and III) MSS tumors $(n=267)$, respectively, and expression rates for these proteins were significantly different in MSI tumors, for which these rates were $32.3 \%, 58.5 \%, 24.2 \%$, and $67.2 \%$, respectively (all $P$ values $<0.01)$.

In patients with MSS tumors, univariate analysis revealed high expression of p53 and AURKA to be significantly associated with disease recurrence rate ( $P=0.01$ and $P<0.01$, respectively; Fig. $3 \mathrm{a}$ and $\mathrm{b}$, respectively). 
TABLE 2 Protein expression and recurrence rate in 386 stage II and III colon cancer patients

\begin{tabular}{|c|c|c|c|c|c|c|c|c|c|}
\hline \multirow[t]{2}{*}{ Expression } & \multicolumn{3}{|c|}{ Overall $(n=386)$} & \multicolumn{3}{|c|}{ Stage II $(n=226)$} & \multicolumn{3}{|c|}{ Stage III $(n=160)$} \\
\hline & $n$ & $\begin{array}{l}\text { Recurrence } \\
\text { rate }(\%)\end{array}$ & $P$ & $n$ & $\begin{array}{l}\text { Recurrence } \\
\text { rate }(\%)\end{array}$ & $P$ & $n$ & $\begin{array}{l}\text { Recurrence } \\
\text { rate }(\%)\end{array}$ & $P$ \\
\hline \multicolumn{10}{|l|}{ p21 } \\
\hline High & 154 & 25.3 & & 96 & 15.6 & & 58 & 41.4 & \\
\hline Low & 219 & 37.9 & 0.01 & 123 & 30.1 & 0.01 & 96 & 47.9 & 0.43 \\
\hline \multicolumn{10}{|l|}{ p27 } \\
\hline High & 278 & 30.9 & & 166 & 22.3 & & 112 & 43.8 & \\
\hline Low & 101 & 36.6 & 0.30 & 57 & 28.1 & 0.38 & 44 & 47.7 & 0.65 \\
\hline \multicolumn{10}{|l|}{ p53 } \\
\hline High & 176 & 40.3 & & 98 & 28.6 & & 78 & 55.1 & \\
\hline Low & 203 & 26.6 & $<0.01$ & 123 & 20.3 & 0.15 & 80 & 36.3 & 0.02 \\
\hline \multicolumn{10}{|c|}{ EGFR membranous } \\
\hline High & 283 & 32.5 & & 167 & 24.0 & & 116 & 44.8 & \\
\hline Low & 95 & 34.7 & 0.69 & 53 & 24.5 & 0.93 & 42 & 47.6 & 0.76 \\
\hline \multicolumn{10}{|c|}{ EGFR cytoplasmic } \\
\hline High & 240 & 32.5 & & 146 & 25.3 & & 94 & 43.6 & \\
\hline Low & 138 & 34.1 & 0.76 & 74 & 21.6 & 0.54 & 64 & 48.4 & 0.55 \\
\hline \multicolumn{10}{|l|}{ Her2/Neu } \\
\hline High & 110 & 27.3 & & 64 & 21.9 & & 46 & 34.8 & \\
\hline Low & 266 & 34.6 & 0.17 & 156 & 23.7 & 0.77 & 110 & 50.0 & 0.08 \\
\hline \multicolumn{10}{|l|}{$\mathrm{Ki}-67$} \\
\hline High & 267 & 31.8 & & 157 & 21.7 & & 110 & 46.4 & \\
\hline Low & 117 & 35.0 & 0.54 & 68 & 27.9 & 0.31 & 49 & 44.9 & 0.86 \\
\hline \multicolumn{10}{|l|}{ Cyclin D1 } \\
\hline High & 168 & 26.8 & & 101 & 17.8 & & 67 & 40.3 & \\
\hline Low & 211 & 36.5 & 0.04 & 122 & 27.9 & 0.08 & 89 & 48.3 & 0.32 \\
\hline \multicolumn{10}{|l|}{ TS } \\
\hline High & 223 & 28.7 & & 141 & 22.7 & & 82 & 39.0 & \\
\hline Low & 160 & 37.5 & 0.07 & 84 & 23.8 & 0.85 & 76 & 52.6 & 0.09 \\
\hline \multicolumn{10}{|c|}{$\beta$-Catenin (nuclear) } \\
\hline High & 137 & 30.7 & & 86 & 23.3 & & 51 & 43.1 & \\
\hline Low & 241 & 34.9 & 0.41 & 133 & 24.8 & 0.79 & 108 & 47.2 & 0.63 \\
\hline \multicolumn{10}{|l|}{ AURKA } \\
\hline High & 264 & 36.0 & & 146 & 24.7 & & 118 & 50.0 & \\
\hline Low & 89 & 19.1 & $<0.01$ & 62 & 17.7 & 0.28 & 27 & 22.2 & $<0.01$ \\
\hline
\end{tabular}

For each protein expression analysis, samples were excluded when insufficient amounts of tissue were available for evaluation of protein expression

Stage II Patients with MSS Tumors When excluding patients who received adjuvant chemotherapy $(n=24)$ from all MSS stage II patients $(n=147)$, those with p53high tumors developed more recurrences than patients with p53-low tumors, although statistical significance was not reached $(36.7 \%$ vs. $21.3 \%, P=0.06)$. Furthermore, those with p21-low tumors exhibited significantly more recurrences than patients with p21-high tumors $(36.0 \%$ vs. $15.9 \%, P=0.02)$.
Stage III Patients with MSS Tumors In MSS stage III patients $(n=120)$, high p53 expression was associated with worse outcome especially in patients who did not receive adjuvant chemotherapy $(n=51)$ as those with $\mathrm{p} 53$ high tumors developed recurrence in $66.7 \%$ compared to $25.9 \%$ in case of p53-low tumors $(P<0.01)$. DFS of stage III patients with high p53 expressing tumors who received chemotherapy was not different from those without chemotherapy $(P=0.2)$. DFS was also similar between 
a

Cumulative disease free survival

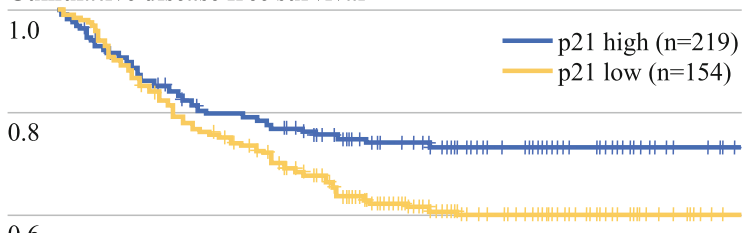

0.4

0.2

Log rank: 5.1

$\mathrm{P}=0.02$

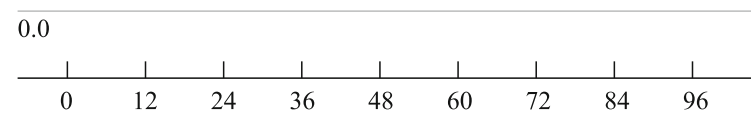

Time after surgery (months)

Cumulative disease free survival

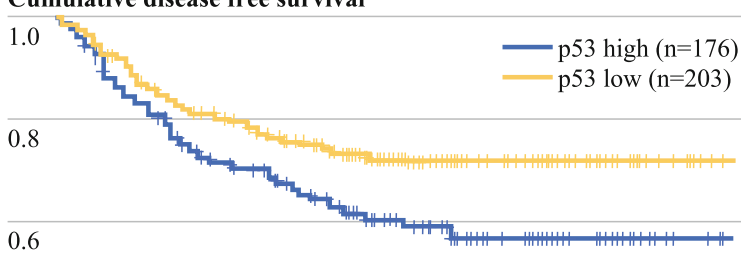

0.4

0.2

Log rank: 7.0

$\mathrm{P}<0.01$

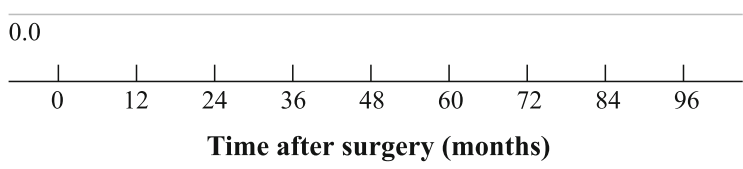

e

Cumulative disease free survival

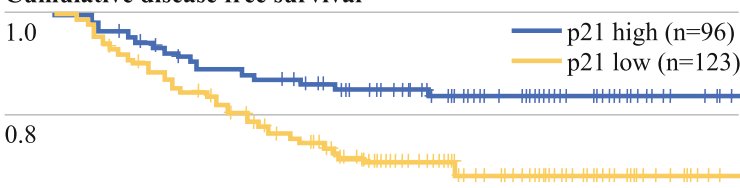

0.6

0.4

0.2

Log rank: 6.2 $P=0.01$

0.0

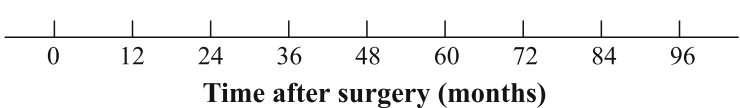

b

Cumulative disease free survival

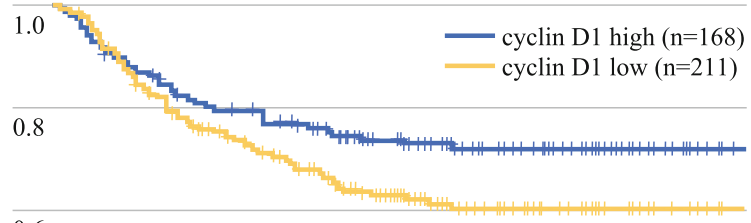

0.6

0.4

0.2

Log rank: 4.0

$\mathrm{P}=0.04$

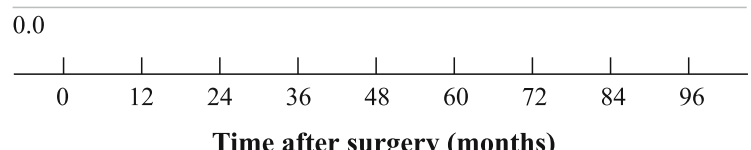

d

Cumulative disease free survival

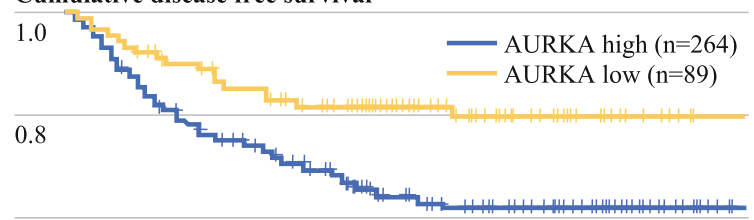

0.6

0.4

0.2

Log rank: 8.4 $\mathrm{P}<0.01$

0.0

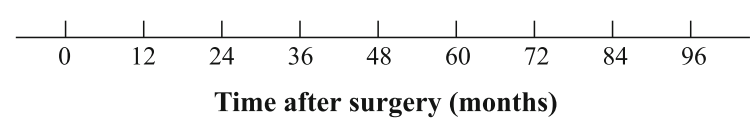

f

Cumulative disease free survival

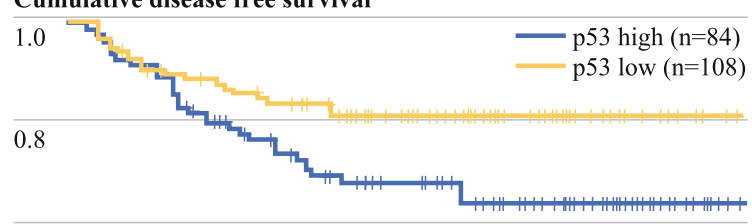

0.6

0.4

0.2

Log rank: 5.3 $\mathrm{P}=0.02$

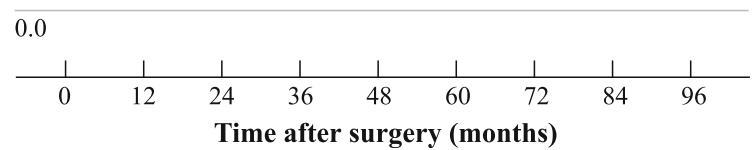


4 FIG. 1 DFS curves for stage II and III colon cancer patients $(n=386)$ according to protein expression levels of a p21, b cyclin D1, c p53, and d AURKA and DFS curves for only stage II patients $(n=226)$ according to expression levels of $\mathbf{e} \mathrm{p} 21$ and $\mathbf{f} \mathrm{p} 53$ (patients with adjuvant chemotherapy excluded). Patients were excluded from protein expression analysis when insufficient amounts of tissue were available for evaluation of protein expression levels

patients with low p53 tumors receiving chemotherapy and those without chemotherapy $(P=0.5)$. DFS curves are displayed in Fig. 4a.

For AURKA, difference in recurrence rates in stage III patients with MSS tumors was mainly attributable to patients who did receive adjuvant chemotherapy (AURKAhigh $53.1 \%$ recurrence, AURKA-low $20.0 \%$ recurrence; $(P=0.02)$. DFS of stage III patients with high AURKA expressing tumors who received chemotherapy was not different from those without chemotherapy $(P=0.9)$. DFS

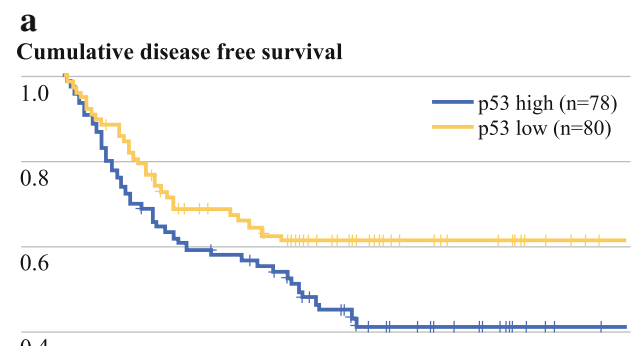

0.4

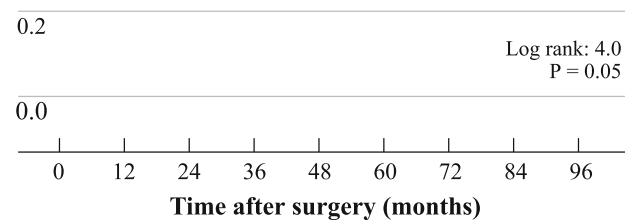

c
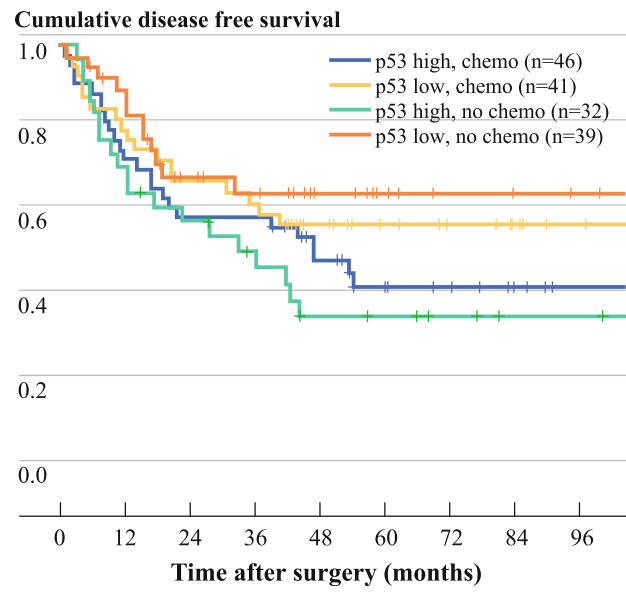

FIG. 2 DFS curves for stage III colon cancer patients according to protein expression levels of p53 (a, c) and AURKA (b, d). Stratification to adjuvant chemotherapy (chemotherapy ["chemo"], no chemotherapy ["no chemo"]) (c, d). (c) p53 high, no chemo vs. p53 low, no chemo (log rank 4.0, $P=0.05)$. (d) AURKA high, was also similar between patients with low AURKA tumors receiving chemotherapy and those without chemotherapy $(P=0.8)$. DFS curves are displayed in Fig. $4 \mathrm{~b}$.

Patients with MSI Tumors In the total population (stage II and III) with MSI tumors $(n=65)$, no significant associations were found between protein expression and disease recurrence.

\section{DISCUSSION}

In the present study, usefulness of cell cycle-associated proteins as prognostic markers was investigated in stage II and III colon cancer. Low p21, low cyclin D1, high p53, and high AURKA expression were found to be associated with worse outcome.

b
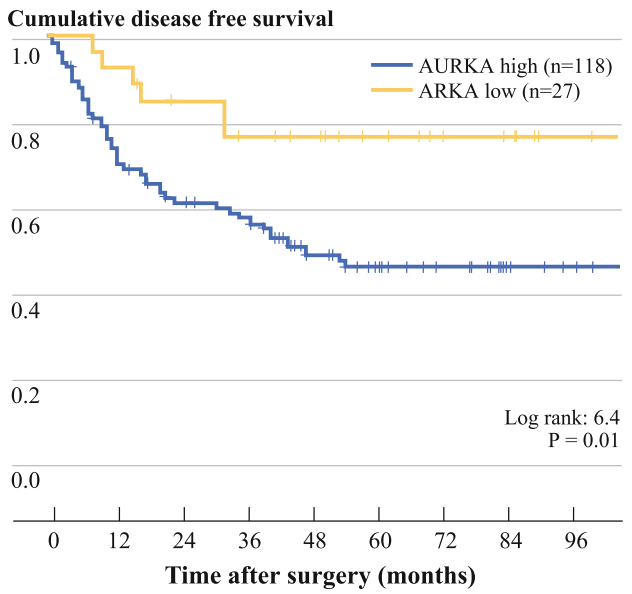

d

Cumulative disease free survival

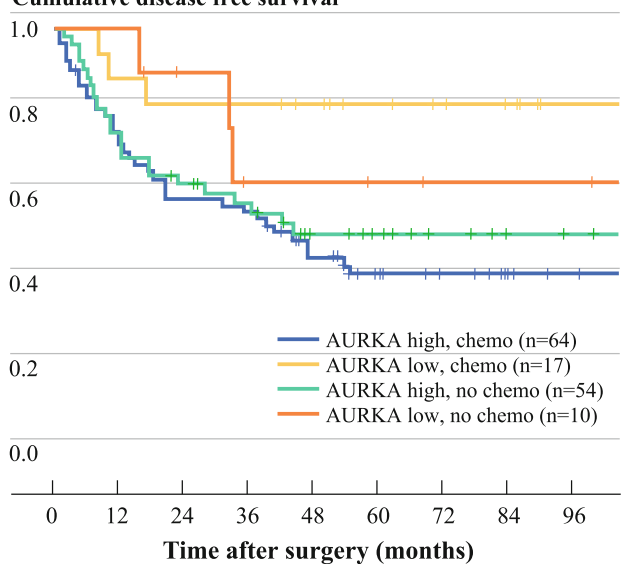

chemo vs. AURKA low, chemo (log rank $6.1, P=0.01)$. Patients were excluded from protein expression analysis when insufficient amounts of tissue were available for evaluation of protein expression levels 
FIG. 3 DFS curves for MSS stage II and III $(n=267)$ colon cancer patients according to protein expression levels of $\mathrm{p} 53$ (a) and AURKA (b). Patients were excluded from protein expression analysis when insufficient amounts of tissue were available for evaluation of protein expression levels a

Cumulative disease free survival

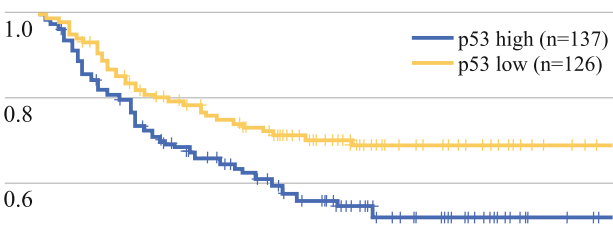

0.4
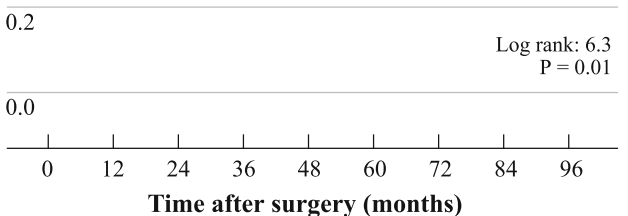

b Cumulative disease free survival

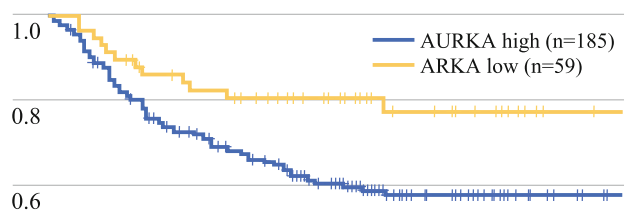
0.6 0.4

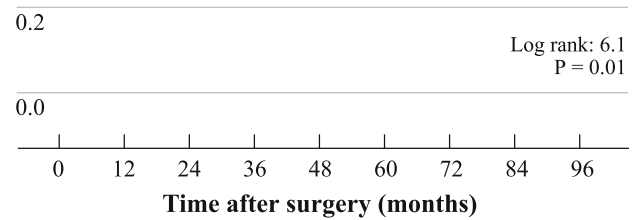

a

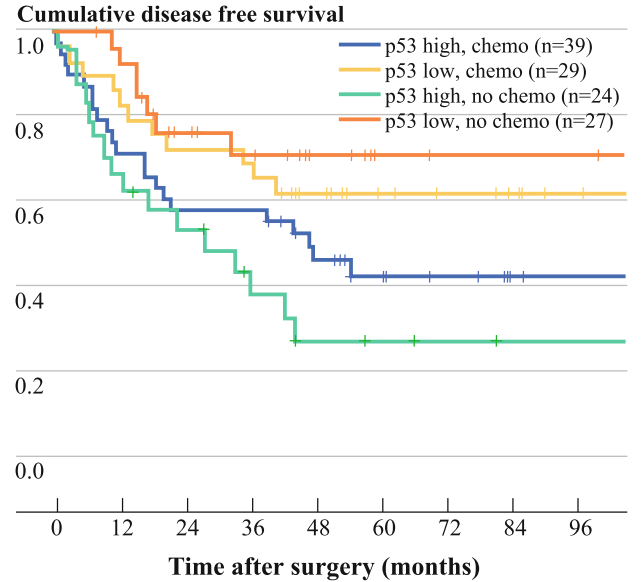

FIG. 4 DFS curves for stage III MSS patients according to protein expression levels of p53: (a) and AURKA: (b) stratified to adjuvant chemotherapy treatment (chemotherapy ["chemo"], no chemotherapy ["no chemo"]). a p53 high, no chemo vs. p53 low, no chemo (log

As the "guardian of the genome," p53 functions as a tumor suppressor by inducing temporary cell cycle arrest to facilitate repair mechanisms when DNA damage occurs or it can induce apoptosis when damage seems irreparable. ${ }^{12,13}$ Loss of these crucial functions leads to replication of defective DNA, genomic instability and progression to cancer. Mutation of the p53 gene occurs in over $50 \%$ of human tumors including sporadic colorectal cancer. ${ }^{14,15}$ It should be noted that the short half-life of wild-type p53 protein normally renders it undetectable by IHC, and that high p53 expression is caused by "mutated p53," which is due to protein-stabilizing conformational alteration. ${ }^{16}$ A systematic review on p53 abnormalities in colorectal cancer underlines that conflicting results have been reported. ${ }^{17}$ Concluded was that overall, abnormal p53 has an adverse effect on outcome in patients with better underlying b

Cumulative disease free survival

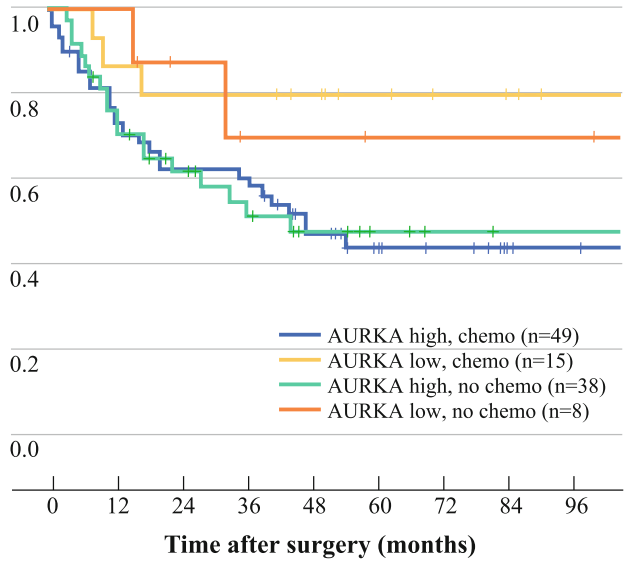

rank 7.8, $P<0.01$. b AURKA high, chemo vs. AURKA low, chemo ( $\log$ rank 4.3, $P=0.04$. Patients were excluded from protein expression analysis when insufficient amounts of tissue were available for evaluation of protein expression levels

prognosis and no effect on outcome in patients treated with 5-fluorouracil-based chemotherapy. The results of the present study are in line with these conclusions as high (presumably mutated) p53 expression was significantly associated with recurrence in stage II patients who did not receive adjuvant chemotherapy.

The p21-gene is the primary mediator of p53-induced cell cycle arrest as p21-protein functions as inhibitor of G1 cyclin-dependent kinases (CDKs) and regulates entry of cells into S-phase. ${ }^{18}$ Cells lacking functional p53 express only low levels of $\mathrm{p} 21$. This is supported by the present study showing a significant association between high, likely nonfunctional p53 and low p21 levels. Abnormal p21 protein levels have been documented in colon cancer patients, but mostly in small and heterogeneous patient populations with contradictory conclusions. ${ }^{19-23}$ In the 
present study, low p21 expression was independently associated with recurrent disease, mostly attributable to stage II patients. We found high p21 expression to be associated with MSI genotype and this relation is confirmed by other studies. ${ }^{23-25}$

Cyclin D1 plays a key role in cell cycle control, as it complexes with CDKs in the G1-phase resulting in S-phase entry. ${ }^{26}$ Cyclin D1 activation by APC mutation/WNT signaling seems to contribute to colon neoplasia initiation. ${ }^{27}$ Despite a well-established role of cyclin D1 in cell cycle progression, previous data on cyclin D1 and clinical outcome in colon cancer have been conflicting, and most previous studies had small and heterogeneous study populations. Although in two studies cyclin D1 overexpression has been associated with poor prognosis and in another two studies with good prognosis, most studies have shown no prognostic value of cyclin D1 overexpression..$^{19,22,28-31}$ In the present study, cyclin D1 overexpression was associated with improved outcome. The biological background supporting this association remains subject of debate. As suggested previously, in order to acquire enhanced malignant characteristics, cyclin D1 negative cancers might have bypassed the necessity of cyclin D1 activation, resulting in more aggressive behavior than cyclin D1-activated cancers. ${ }^{31}$ Previously, cyclin D1 has been described to be overexpressed in MSI colorectal cancers, as in the present study. ${ }^{32}$

The Aurora kinase family is a collection of highly related serine/threonine kinases that are key regulators of mitosis. Aurora has evolved into three related kinases known as Aurora kinase A, B, and C. The Aurora kinase A protein (AURKA) is a centrosome-associated protein and has been implicated in regulatory centrosome function, spindle assembly, chromosome segregation and cytokinesis. ${ }^{33,34}$ AURKA positively regulates the $\mathrm{G} 2$ to $M$ phase of the cell cycle and activation of AURKA in late G2 is inhibited by DNA damage. ${ }^{33}$ Activation of AURKA in experimental systems confers malignant phenotype by inducing centrosome amplification and genomic instability, indicating AURKA as an oncogene. ${ }^{35}$ The gene for AURKA is located on chromosome 20q13.2, a region commonly amplified in malignancies. ${ }^{33,36}$ Amplification of AURKA mRNA has been found in many human tumors, including colorectal cancer. ${ }^{33,37,38}$

Few studies are available addressing the association between AURKA and outcome in colorectal cancer patients. Two studies didn't find a significant association between AURKA and survival. ${ }^{39,40}$ These studies described 517 and 200 tissue samples, respectively, both from stage I to IV colon and rectal cancer patients without including chemotherapy and radiotherapy in the analysis. ${ }^{39}$ Another study showed worse survival for patients with AURKA-high tumors, but the study population was small $(n=55)$ and heterogeneous (stage I to IV colon and rectal cancers). ${ }^{41}$

In the present study, high AURKA expression was significantly associated with recurrence in a large, homogeneous cohort of colon cancer patients. Many studies have investigated expression levels of cell cycle proteins and clinical outcome in colorectal cancer patients reporting conflicting results. ${ }^{22,42-50}$ Most studies describe heterogeneous patient populations without stratification for tumor localization (colon vs. rectum) and MSI status and without multivariate analysis. Furthermore, the choice of scoring method and selection of cutoff values for immunoreactivity is rarely described. The present study described a large, homogeneous cohort stage II and III colon cancer patients, including MSI status and multivariate analysis. ROC curves were used to select cutoff values because this is an established method in clinical oncology to evaluate sensitivity and specificity of diagnostic tests. ${ }^{51,52}$ It has proven to be useful in determining clinically relevant thresholds for immunohistochemical tumor positivity in biomarker studies. ${ }^{10,53}$ Of course, before these markers can be used in a clinical setting, validation studies that use the same immunohistochemical techniques and scoring methods are necessary to proof generalizability.

In conclusion, in the present study, low p21, high p53, low cyclin D1, and high AURKA were associated with disease recurrence in stage II and III colon cancer patients. These proteins could possibly be used as prognostic markers to identify patients with high risk of recurrence and help to decide whether or not adjuvant chemotherapy should be offered.

ACKNOWLEDGMENT Supported in part by a grant from the Posthumus Meyjes Foundation of the Kennemer Gasthuis hospital, Haarlem, The Netherlands.

OPEN ACCESS This article is distributed under the terms of the Creative Commons Attribution License which permits any use, distribution, and reproduction in any medium, provided the original author(s) and the source are credited.

\section{REFERENCES}

1. Sobin L, Gospodarowicz M, Wittekind C. TNM classification of malignant tumours. 7th ed. New York: Wiley; 2009.

2. Gill S, Loprinzi CL, Sargent DJ, et al. Pooled analysis of fluorouracil-based adjuvant therapy for stage II and III colon cancer: who benefits and by how much? J Clin Oncol. 2004;22: 1797-806.

3. Mamounas E, Wieand S, Wolmark N, et al. Comparative efficacy of adjuvant chemotherapy in patients with Dukes' B versus Dukes' C colon cancer: results from four National Surgical Adjuvant Breast and Bowel Project adjuvant studies (C-01, C-02, C-03, and C-04). J Clin Oncol. 1999;17:1349-55.

4. International Multicentre Pooled Analysis of B2 Colon Cancer Trials (IMPACT B2) Investigators. Efficacy of adjuvant 
fluorouracil and folinic acid in B2 colon cancer. J Clin Oncol. 1999; 17:1356-63.

5. Hanahan D, Weinberg RA. The hallmarks of cancer. Cell. 2000;100:57-70.

6. Hermanek P, Sobin LH. International Union Against Cancer (UICC): TNM classification of malignant tumours. 4th ed. New York: Springer; 1987.

7. Simon R, Mirlacher M, Sauter G. Tissue microarrays. Biotechniques. 2004;36:98-105.

8. Lagendijk JH, Mullink H, van Diest PJ, Meijer GA, Meijer CJ. Immunohistochemical differentiation between primary adenocarcinomas of the ovary and ovarian metastases of colonic and breast origin. Comparison between a statistical and an intuitive approach. J Clin Pathol. 1999;52:283-90.

9. Jacobs TW, Gown AM, Yaziji H, Barnes MJ, Schnitt SJ. Specificity of HercepTest in determining HER-2/neu status of breast cancers using the United States Food and Drug Administrationapproved scoring system. J Clin Oncol. 1999;17:1983-7.

10. Zlobec I, Steele R, Terracciano L, Jass JR, Lugli A. Selecting immunohistochemical cut-off scores for novel biomarkers of progression and survival in colorectal cancer. J Clin Pathol. 2007;60:1112-6.

11. Weiss MM, Hermsen MA, Meijer GA, et al. Comparative genomic hybridisation. Mol Pathol. 1999;52:243-51.

12. Lane DP. Cancer: p53, guardian of the genome. Nature. 1992; 358:15-6.

13. Balint EE, Vousden KH. Activation and activities of the p53 tumour suppressor protein. Br J Cancer. 2001;85:1813-23.

14. Hollstein M, Sidransky D, Vogelstein B, Harris CC. p53 mutations in human cancers. Science. 1991;253:49-53.

15. Rodrigues NR, Rowan A, Smith ME, et al. p53 mutations in colorectal cancer. Proc Natl Acad Sci USA. 1990;87:7555-9.

16. Baas IO, Mulder JW, Offerhaus GJ, Vogelstein B, Hamilton SR. An evaluation of six antibodies for immunohistochemistry of mutant p53 gene product in archival colorectal neoplasms. J Pathol. 1994;172:5-12.

17. Munro AJ, Lain S, Lane DP. P53 abnormalities and outcomes in colorectal cancer: a systematic review. Br J Cancer. 2005;92: 434-44.

18. Harper JW, Adami GR, Wei N, Keyomarsi K, Elledge SJ. The p21 Cdk-interacting protein Cip1 is a potent inhibitor of G1 cyclin-dependent kinases. Cell. 1993;75:805-16.

19. Bukholm IK, Nesland JM. Protein expression of p53, p21 (WAF1/CIP1), bcl-2, Bax, cyclin D1 and pRb in human colon carcinomas. Virchows Arch. 2000;436:224-8.

20. Sinicrope FA, Roddey G, Lemoine M, et al. Loss of p21WAF1/ Cip1 protein expression accompanies progression of sporadic colorectal neoplasms but not hereditary nonpolyposis colorectal cancers. Clin Cancer Res. 1998;4:1251-61.

21. Elkablawy MA, Maxwell P, Williamson K, Anderson N, Hamilton PW. Apoptosis and cell-cycle regulatory proteins in colorectal carcinoma: relationship to tumour stage and patient survival. J Pathol. 2001;194:436-43.

22. Lyall MS, Dundas SR, Curran S, Murray GI. Profiling markers of prognosis in colorectal cancer. Clin Cancer Res. 2006;12: 1184-91.

23. Ogino S, Nosho K, Shima K, et al. p21 expression in colon cancer and modifying effects of patient age and body mass index on prognosis. Cancer Epidemiol Biomarkers Prev. 2009;18: 2513-21.

24. Edmonston TB, Cuesta KH, Burkholder S, et al. Colorectal carcinomas with high microsatellite instability: defining a distinct immunologic and molecular entity with respect to prognostic markers. Hum Pathol. 2000;31:1506-14.

25. Ogino S, Kawasaki T, Kirkner GJ, et al. Down-regulation of p21 (CDKN1A/CIP1) is inversely associated with microsatellite instability and $\mathrm{CpG}$ island methylator phenotype (CIMP) in colorectal cancer. J Pathol. 2006;210:147-54.

26. Hunter T, Pines J. Cyclins and cancer II: cyclin D and CDK inhibitors come of age. Cell. 1994;79:573-82.

27. Tetsu O, McCormick F. Beta-catenin regulates expression of cyclin D1 in colon carcinoma cells. Nature. 1999;398:422-6.

28. Bahnassy AA, Zekri AR, El-Houssini S, et al. Cyclin A and cyclin D1 as significant prognostic markers in colorectal cancer patients. BMC Gastroenterol. 2004;4:22.

29. Holland TA, Elder J, McCloud JM, et al. Subcellular localisation of cyclin D1 protein in colorectal tumours is associated with p21(WAF1/CIP1) expression and correlates with patient survival. Int J Cancer. 2001;95:302-6.

30. Maeda K, Chung YS, Kang SM, et al. Overexpression of cyclin D1 and p53 associated with disease recurrence in colorectal adenocarcinoma. Int J Cancer. 1997;74:310-5.

31. Ogino S, Nosho K, Irahara N, et al. A cohort study of cyclin D1 expression and prognosis in 602 colon cancer cases. Clin Cancer Res. 2009;15:4431-8.

32. Nosho K, Kawasaki T, Chan AT, et al. Cyclin D1 is frequently overexpressed in microsatellite unstable colorectal cancer, independent of $\mathrm{CpG}$ island methylator phenotype. Histopathology. 2008;53:588-98.

33. Marumoto T, Zhang D, Saya H. Aurora-A-a guardian of poles. Nat Rev Cancer. 2005;5:42-50.

34. Katayama H, Brinkley WR, Sen S. The Aurora kinases: role in cell transformation and tumorigenesis. Cancer Metastasis Rev. 2003;22:451-64.

35. Zhou H, Kuang J, Zhong L, et al. Tumour amplified kinase STK15/BTAK induces centrosome amplification, aneuploidy and transformation. Nat Genet. 1998;20:189-93.

36. De Angelis PM, Stokke T, Beigi M, Mjaland O, Clausen OP. Prognostic significance of recurrent chromosomal aberrations detected by comparative genomic hybridization in sporadic colorectal cancer. Int J Colorectal Dis. 2001;16:38-45.

37. Bischoff JR, Anderson L, Zhu Y, et al. A homologue of Drosophila Aurora kinase is oncogenic and amplified in human colorectal cancers. EMBO J. 1998;17:3052-65.

38. Carvalho B, Postma C, Mongera S, et al. Multiple putative oncogenes at the chromosome 20q amplicon contribute to colorectal adenoma to carcinoma progression. Gut. 2009;58:79-89.

39. Baba Y, Nosho K, Shima K, et al. Aurora-A expression is independently associated with chromosomal instability in colorectal cancer. Neoplasia. 2009;11:418-25.

40. Lam AK, Ong K, Ho YH. Aurora kinase expression in colorectal adenocarcinoma: correlations with clinicopathological features, p16 expression, and telomerase activity. Hum Pathol. 2008; 39:599-604.

41. Burum-Auensen E, DeAngelis PM, Schjolberg AR, Roislien J, Mjaland O, Clausen OP. Reduced level of the spindle checkpoint protein BUB1B is associated with aneuploidy in colorectal cancers. Cell Prolif. 2008;41:645-59.

42. Galizia G, Lieto E, Ferraraccio F, et al. Determination of molecular marker expression can predict clinical outcome in colon carcinomas. Clin Cancer Res. 2004;10:3490-9.

43. Rosati G, Chiacchio R, Reggiardo G, De Sanctis D, Manzione L. Thymidylate synthase expression, p53, bcl-2, Ki-67 and p27 in colorectal cancer: relationships with tumor recurrence and survival. Tumour Biol. 2004;25:258-63.

44. Allegra CJ, Paik S, Colangelo LH, et al. Prognostic value of thymidylate synthase, Ki-67, and p53 in patients with Dukes' B and C colon cancer: a National Cancer Institute-National Surgical Adjuvant Breast and Bowel Project collaborative study. J Clin Oncol. 2003;21:241-50.

45. Buglioni S, D’Agnano I, Cosimelli M, et al. Evaluation of multiple bio-pathological factors in colorectal adenocarcinomas: 
independent prognostic role of p53 and bcl-2. Int J Cancer. 1999;84:545-52.

46. Spano JP, Fagard R, Soria JC, Rixe O, Khayat D, Milano G. Epidermal growth factor receptor signaling in colorectal cancer: preclinical data and therapeutic perspectives. Ann Oncol. 2005; 16:189-94.

47. McKay JA, Loane JF, Ross VG, et al. c-erbB-2 is not a major factor in the development of colorectal cancer. $\mathrm{Br} J$ Cancer. 2002;86:568-73.

48. Popat S, Matakidou A, Houlston RS. Thymidylate synthase expression and prognosis in colorectal cancer: a systematic review and meta-analysis. J Clin Oncol. 2004;22:529-36.

49. Chung GG, Provost E, Kielhorn EP, Charette LA, Smith BL, Rimm DL. Tissue microarray analysis of beta-catenin in colorectal cancer shows nuclear phospho-beta-catenin is associated with a better prognosis. Clin Cancer Res. 2001;7:4013-20.
50. Lugli A, Zlobec I, Minoo P, et al. Prognostic significance of the wnt signalling pathway molecules APC, beta-catenin and E-cadherin in colorectal cancer: a tissue microarray-based analysis. Histopathology. 2007;50:453-64.

51. Hanley JA. Receiver operating characteristic (ROC) methodology: the state of the art. Crit Rev Diagn Imaging. 1989;29: 307-35.

52. Lind PA, Wennberg B, Gagliardi G, et al. ROC curves and evaluation of radiation-induced pulmonary toxicity in breast cancer. Int J Radiat Oncol Biol Phys. 2006;64:765-70.

53. Zlobec I, Vuong T, Hayashi S, et al. A simple and reproducible scoring system for EGFR in colorectal cancer: application to prognosis and prediction of response to preoperative brachytherapy. Br J Cancer. 2007;96:793-800. 